\title{
Параинформационные приемы и стратегии СМИ в освещении катастроф природного характера
}

Мария Королева

В статье рассматривается особая категория параинформационных приемов СМИ, направленных на возбуждение тревоги, страха и гнева как особо сильных эмоций в освещении стихийных бедствий. Показана взаимосвязь между использованием подобных способов и развлекательным характером издания. Кроме того, выявлены различия в способах подачи новостей изданиями, относящимися к разным «поколениям» медиа. Выдвигается гипотеза о «генотипическом» расхождении традиционных и новых медиа.

Ключевые слова: медиапсихология, СМИ, user generated content, параинформационные приемы, стихийные бедствия.
(C) Королева Мария Николаевна аспирантка кафедры периодической печати факультета журналистики МГУ имени М.В. Ломоносова (г. Москва, Россия), mary-1993_93@mail.ru

\section{Введение}

Деятельность СМИ придает любому стихийному бедствию общественный резонанс, который либо усиливает катастрофичность последствий, либо способствует скорейшему их преодолению (Бервенова, 2007: 3-4). Многие СМИ стремятся подать информацию о стихийных бедствиях зрелищно и ярко. Однако культивация таких чувств, как тревога, растерянность, страх, гнев, отчаяние может оказывать сильное дезорганизующее и деморализующее влияние на человека, и подобные манипуляции в массовой коммуникации представляют особый риск. Активное тиражирование в медиапространстве эмоциогенных сообщений о природных бедствиях может вызвать эффект «выученной беспомощности» и, как следствие, привести к апатичному или паническому поведению людей непосредственно во время катаклизмов. Поэтому мы, разделяя точку зрения исследователей (Пронина, 2011; Рыбалко, 2007; Трубицына, 2001), считаем необходимым для работников СМИ понимать цели сообщения и учитывать степень безопасности приемов подачи информации журналистами о катастрофах.

Чтобы привлечь внимание к изданию и установить с читателем эмоциональный контакт, журналисты применяют параин- 
формационные приемы - выразительные средства сообщения, которые предназначены не столько для передачи конкретных сведений, фактов, сколько для формирования отношения к ним. Такие приемы задают рамки восприятия и оценки действительности, но сами информацией (о внешнем мире) не являются (Конецкая, 1997). Именно эти приемы стали предметом нашего исследования.

Намеренное злоупотребление параинформационными приемами, направленными на нагнетание отрицательных эмоций, таких как, например, страх, тревога, отчаяние, можно охарактеризовать как своеобразную форму «информационного садизма». В своей статье «О негативном влиянии средств массовой информации на психическое здоровье» известный психиатр Ю.И. Полищук (2003: 63) приравнивает к садизму «подробное описание издевательств преступника над жертвой, ее страданий и смерти». В контексте данной работы под информационным садизмом понималось подробное описание страданий и смерти людей в результате экстремального природного явления.

Не все параинформационные приемы используются с целью педалирования негативных эмоций и вызывают травматический эффект. Например, подобные приемы, представляющие ситуацию как трудную, но решаемую, оказывают положительное воздействие на психоэмоциональное состояние массовой аудитории, содействуют психологической мобилизации, готовности к сопротивлению обстоятельствам и преодолению трудностей. В нашем исследовании мы рассмотрели в том числе и параинформационные приемы, которые представляют компенсаторные, медиатерапевтические ресурсы СМИ.

\section{Методика}

В качестве исследовательской гипотезы было выдвинуто предположение, что характер представления стихийных бедствий и количество используемых параинформационных приемов отличаются в разных изданиях и зависят от их направленности и активности использования новых технологий.

Основу эмпирической базы исследования составили публикации онлайн-платформ «Российской газеты» - RG.ru (https://rg.ru), «Комсомольской правды» - KP.ru (https:/ www.kp.ru), Lenta.ru (https://lenta.ru), посвященные резонансным (привлекшим повышенное внимание (МИ) экстремальным природным явлениям на территории РФ в период с 1 января по 31 декабря 2017 г. В рейтинге самых цитируемых интернетресурсов, по данным «Медиалогии» за октябрь 2017 г.1, эти платформы занимали 29-е, шестое и третье место. На январь 2019 г. RG.ru и Lenta.ru утратили свои позиции (RG. ru выбыла из рейтинга; Lenta.ru перешла на четвертое место), в то время как KP.ru поднялась на строчку выше (пятое место)².

Тем не менее в ходе исследования были проанализированы 199 рейтинговых публикаций на трех онлайн-платформах (102 - RG.ru, 83 - KP.ru, 14 - Lenta.ru) объемом более 1500 знаков за указанный выше период.

Кодификатор контент-анализа включал в себя 15 категорий признаков (разбитых на 101 подкатегорию). 15 категорий были объединены в два блока, один из которых отражал тематические аспекты изучаемых медиатекстов, а другой - особенности подачи информации:

- общетематический - состоит из трех категорий (категории 1-3) и отвечает за тематический аспект текста: в какой контекст встроена информация об экстремальном природном явлении, о какой именно природной угрозе идет речь, на территории какого региона она возникла;

- коммуникативный - состоит из двенадцати категорий (категории 4-15) и характеризует особенности подачи информации (см. табл. 1). 
Таблица 1. Кодификатор контент-аналитического исследования

\begin{tabular}{|c|c|c|}
\hline № & Категория (тип категории) & Содержание категории \\
\hline 1 & $\begin{array}{l}\text { Общетематический блок } \\
\text { (тематический) }\end{array}$ & $\begin{array}{l}\text { Экстремальные природные явления (101), общество (102), } \\
\text { политика/власть(103), государство/законодательство (104), } \\
\text { наука (105), экономика/финансирование (106), технологии } \\
\text { (107), образование/воспитание (108), глобальные } \\
\text { экологические изменения и нарушения (109), местные } \\
\text { экологические изменения и нарушения (110), другое (111) }\end{array}$ \\
\hline 2 & $\begin{array}{l}\text { Упоминание природных } \\
\text { угроз (тематический) }\end{array}$ & $\begin{array}{l}\text { Землетрясение (201), наводнение/паводок (202), цунами } \\
\text { (203), буря (204), ураган (205), смерч (206), тайфун (207), } \\
\text { обвал (208), оползень (209), сель (210), снежная лавина } \\
\text { (211), природный пожар (212) }\end{array}$ \\
\hline 3 & $\begin{array}{l}\text { Регион возникновения } \\
\text { (тематический) }\end{array}$ & $\begin{array}{l}\text { Центральный ФО (301), Северо-Западный ФО (302), } \\
\text { Южный ФО (З03), Северо-Кавказский ФО (304), } \\
\text { Приволжский ФО (305), Уральский ФО (306), Сибирский ФО } \\
\text { (307), Дальневосточный ФО (308), вся территория РФ (309) }\end{array}$ \\
\hline 4 & $\begin{array}{l}\text { Субъект мнения в тексте } \\
\text { (коммуникативный) }\end{array}$ & $\begin{array}{l}\text { Журналист (401), очевидцы и участники событий } \\
\text { (402), эксперт (403), власти (404), посторонние (405), } \\
\text { пользователи социальных сетей (406), не указано (407) }\end{array}$ \\
\hline 5 & $\begin{array}{l}\text { Лексико-семантические } \\
\text { параинформационные } \\
\text { приемы } \\
\text { (коммуникативный) } \\
\end{array}$ & $\begin{array}{l}\text { Эпитет (501), оценочная характеристика (502), } \\
\text { метафора (503), сравнительный оборот (504) }\end{array}$ \\
\hline 6 & $\begin{array}{l}\text { Hарративные } \\
\text { параинформационные } \\
\text { приемы } \\
\text { (коммуникативный) }\end{array}$ & $\begin{array}{l}\text { Показ картин разрушений (601), панические интонации } \\
\text { в словах очевидцев (602), страдания людей (603), } \\
\text { сенсационность (604) }\end{array}$ \\
\hline 7 & $\begin{array}{l}\text { Мобилизация } \\
\text { (готовность } \\
\text { к преодолению } \\
\text { трудностей; } \\
\text { коммуникативный) }\end{array}$ & $\begin{array}{l}\text { Государство и власть пытаются решить проблему (701); } \\
\text { организации (например, коммунальные службы, МЧС) } \\
\text { пытаются решить проблему (702); люди (простые граждане, } \\
\text { общественные организации) самостоятельно ликвидируют } \\
\text { последствия экстремального природного явления (703); } \\
\text { не указано (704) }\end{array}$ \\
\hline 8 & $\begin{array}{l}\text { Жанры и способы } \\
\text { подачи информации } \\
\text { (коммуникативный) }\end{array}$ & $\begin{array}{l}\text { Интервью (801); репортаж (802); онлайн-трансляция (803); } \\
\text { статистика (804); инфографика (805); рассказ очевидцев, } \\
\text { участников события (806); наличие фото-, видео- и аудио- } \\
\text { материалов соответственно (807-809) }\end{array}$ \\
\hline 9 & $\begin{array}{l}\text { Источники } \\
\text { аудиовизуального } \\
\text { контента } \\
\text { (коммуникативный) }\end{array}$ & $\begin{array}{l}\text { Издательский (901), организации и их пресс-службы (902), } \\
\text { другие СМИ (903), пользовательский (904), не указано (905) }\end{array}$ \\
\hline 10 & $\begin{array}{l}\text { Показ картин } \\
\text { разрушений в контенте } \\
\text { (коммуникативный) }\end{array}$ & $\begin{array}{l}\text { Заголовок (1001), лид (1002), текст (1003), фото (1004), } \\
\text { видео (1005), аудио (1006) }\end{array}$ \\
\hline 11 & $\begin{array}{l}\text { Панические } \\
\text { интонации в контенте } \\
\text { (коммуникативный) }\end{array}$ & $\begin{array}{l}\text { Заголовок (1101), лид (1102), текст (1103), фото (1104), } \\
\text { видео (1105), аудио (1106) }\end{array}$ \\
\hline 12 & $\begin{array}{l}\text { Страдания } \\
\text { людей в контенте } \\
\text { (коммуникативный) }\end{array}$ & $\begin{array}{l}\text { Заголовок (1201), лид (1202), текст (1203), фото (1204), } \\
\text { видео (1205), аудио (1206) }\end{array}$ \\
\hline 13 & $\begin{array}{l}\text { Сенсационность в контенте } \\
\text { (коммуникативный) }\end{array}$ & $\begin{array}{l}\text { Заголовок (1301), лид (1302), текст (1303), фото (1304), } \\
\text { видео (1305), аудио (1306) }\end{array}$ \\
\hline 14 & $\begin{array}{l}\text { Мобилизация в контенте } \\
\text { (коммуникативный) }\end{array}$ & $\begin{array}{l}\text { Заголовок (1401), лид (1402), текст (1403), фото (1404), } \\
\text { видео (1405), аудио (1406) }\end{array}$ \\
\hline 15 & $\begin{array}{l}\text { Ответственность } \\
\text { (коммуникативный) }\end{array}$ & $\begin{array}{l}\text { Вопрос об ответственности присутствует (1501); речи об } \\
\text { ответственности нет (1502); виноваты власть/чиновники } \\
\text { (1503); организации (1504); люди (1505); } \\
\text { природа/случай (1506) }\end{array}$ \\
\hline
\end{tabular}


В ходе предварительного исследования были выделены следующие параинформационные приемы нагнетания отрицательных эмоций:

-лексико-семантические приемы подбор эмоционально заряженной лексики «для устрашения» (эпитеты: «В Канске во время страшного пожара погибли два человека»; оценочные характеристики: использование слов "ужасно», «катастрофа», «беспредел»; метафоры: «Пламя “пожирало" все новые и новые строения»; сравнительные обороты: «Дома горели, как спички»)3;

- нарративные приемы - используется особая форма изложения событий с фиксацией на страшном, живописание пугающих деталей:

- показ картин разрушений («Ветер вырывал из земли даже остановочные павильоны»);

- панические интонации в словах очевидцев («Туристка из Китая была в очень тяжелом состоянии, ей кричали, чтобы она не закрывала глаза, а она не понимала, что от нее хотят, потому что совсем не знает языка»)4;

- страдания людей («Подруге Даши повезло - она уцелела, а саму девушку, по словам очевидцев, ствол буквально разрубил пополам; кроме того, у нее была оторвана ступня»)5;

- сенсационность («Грозит ли Ставрополью повторение наводнения 2002 года») 6 .

Результаты анализа были сведены в единую матрицу (базу данных), которая затем подвергалась процедурам математической обработки с использованием специализированного программного пакета SPSS IBM Statistics. Применялись процедуры частотного, корреляционного, множественного регрессионного и дискриминантного анализа, непараметрические критерии сравнения выборок (Н Краскала-Уоллиса и U Манна-Уитни).

\section{Использование параинформационных приемов}

Результаты исследования показали, что все проанализированные нами публикации содержали параинформационные приемы: журналисты RG.ru, KP.ru и Lenta.ru активно использовали как нарративные, так и лексико-семантические подобные приемы. Общее их число в среднем на статью для каждого издания составило: RG.ru - 3,9; KP.ru - 4,8; Lenta.ru - 5,1.

Оценивая значимость различий по количеству параинформационных приемов в разных изданиях с помощью критерия попарного сравнения групп U Манна-Уитни, мы выяснили, что Lenta.ru и KP.ru значимо отличаются от RG.ru, в текстах которой было обнаружено меньше всего параинформационных приемов. Такие же результаты были получены и в ходе частотного анализа. Таким образом, основная гипотеза нашего исследования о различиях в интенсивности использования параинформационных приемов в исследуемых изданиях подтвердилась (см. табл. 2). Наименьшее количество параинформационных приемов было обнаружено в материалах RG.ru, ежедневного правительственного издания. В материалах KP.ru и Lenta.ru, популярных изданиях, ориентированных на интерактивность и массовость, таких приемов оказалось значительно больше.

Содержательный анализ по видам параинформационных приемов (см. рис. 1) показывает, что чаще всего используются такие лексико-семантические приемы, как "эпитет» и «метафора», а из нарративных - «картины разрушений» и «сенсационность». Следовательно, масштаб и значимость природного катаклизма демонстрируется через разрушительный образ бушующей стихии, поражающий воображение аудитории. Хотя описания «страданий людей» используются не слишком часто, они все же встречаются, при этом показатели RG.ru заметно ниже. Детальный 
Таблица 2. Достоверность различий в использовании параинформационных приемов

\begin{tabular}{|l|c|c|c|}
\hline \multirow{2}{*}{ Достоверность различий в использовании параинформационных приемов } \\
\hline \multirow{2}{*}{ Статистический критерий } & RG.ru и KP.ru & RG.ru и Lenta.ru & KP.ru и Lenta.ru \\
\cline { 2 - 4 } Статистика U Манна-Уитни & 2502,5 & 415 & 532,5 \\
\hline Асимпт. знч. (двухсторонняя) & $0^{* *}$ & $0,008^{*}$ & 0,606 \\
\hline
\end{tabular}

* достоверность на уровне $p<0,01$

** достоверность на уровне $p<0,001$

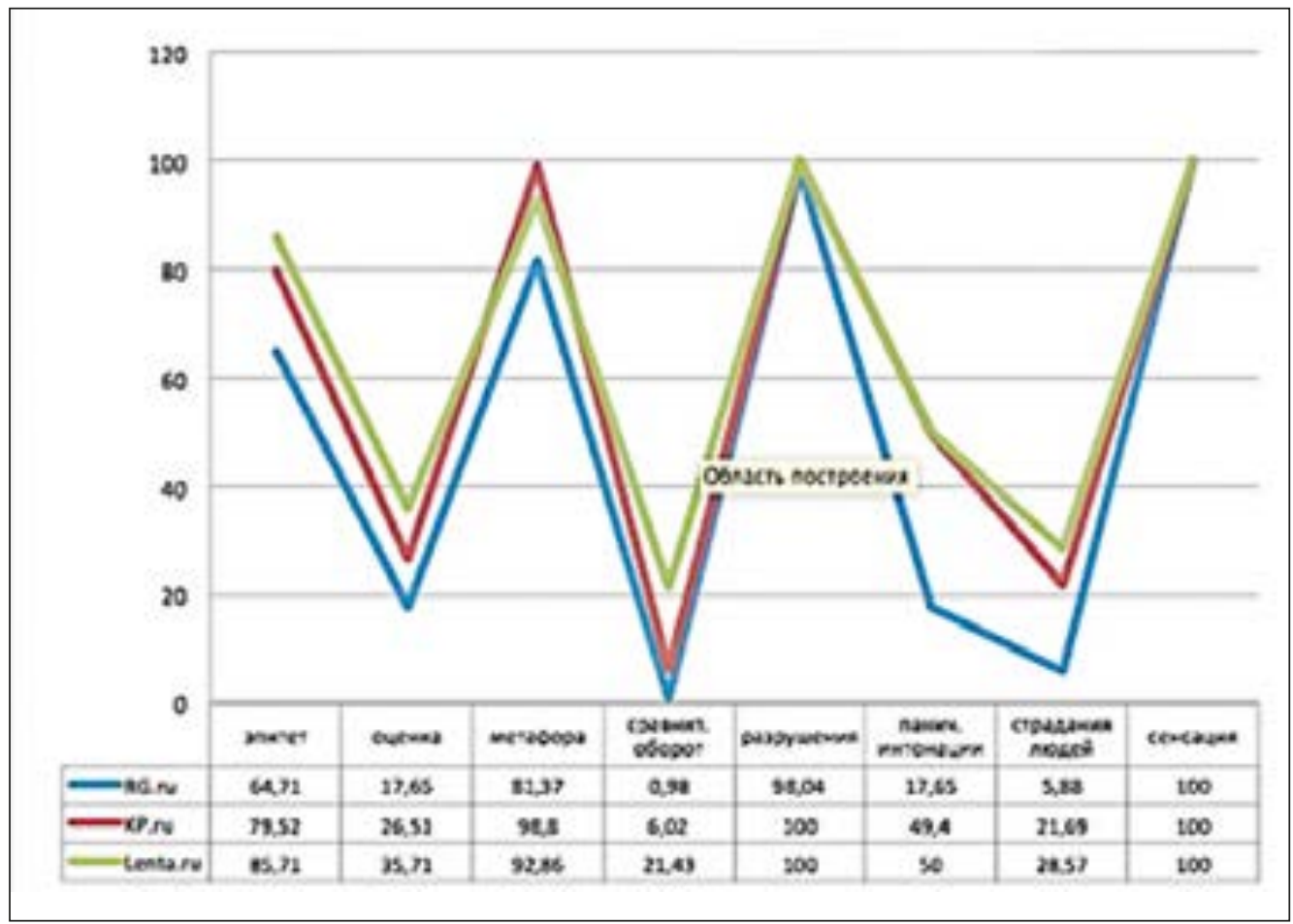

Рисунок 1. Использование параинформационных приемов в разных изданиях (в \% к общ. кол-ву статей)

анализ по критерию U Манна-Уитни показывает, что различия между RG.ru и двумя другими изданиями статистически значимы, в то время как показатели KP.ru и Lenta. ru отличаются несущественно (см. табл. 3).

\section{Феномен «информационного садизма»}

Для того чтобы выяснить, в каком издании тема страданий людей приобретает характер «информационного садизма», мы провели регрессионный анализ, который позволил выявить взаимосвязь категории 603 «Страдания людей» с другими важными категориями контент-анализа. В качестве релевантных были избраны категории, характеризующие «субъекта мнения в тексте» (категории 401-407), «жанры и способы подачи информации» (категории 801-809), «источники аудиовизуального 
Таблица 3. Достоверность различий в количестве описаний страданий людей

\begin{tabular}{|l|c|c|c|}
\hline \multicolumn{4}{|c|}{ Достоверность различий в описании страданий людей } \\
\hline \multirow{2}{*}{ Статистический критерий } & Издания \\
\cline { 2 - 4 } & RG.ru и KP.ru & RG.ru и Lenta.ru & KP.ru и Lenta.ru \\
\hline Статистика U Манна-Уитни & 3564,0 & 552,0 & 541,0 \\
\hline Асимпт. знч. (двухсторонняя) & $0,002^{*}$ & $0,005^{*}$ & 0,571 \\
\hline
\end{tabular}

* достоверность на уровне $p<0,01$

** достоверность на уровне $p<0,001$

Таблица 4. Результаты множественного регрессионного анализа по категории 603 «Страдания людей» (Зависимая переменная: 603 «Страдания людей»)

\begin{tabular}{|c|c|c|c|c|c|}
\hline \multirow[t]{2}{*}{ Издание } & \multirow[t]{2}{*}{ Категория } & \multirow[t]{2}{*}{ Содержание категории } & \multicolumn{2}{|c|}{$\begin{array}{c}\text { Нестандартизованные } \\
\text { коэффициенты }\end{array}$} & \multirow[t]{2}{*}{ Значение } \\
\hline & & & B & Стд. Ошибка & \\
\hline \multirow{3}{*}{ RG.ru } & 808 & Видеоматериалы & 0,311 & 0,09 & 0,001 \\
\hline & 406 & $\begin{array}{l}\text { Субъект мнения - } \\
\text { пользователь }\end{array}$ & 0,292 & 0,09 & 0,002 \\
\hline & 1506 & Виновата природа & 0,114 & 0,056 & 0,043 \\
\hline \multirow{2}{*}{ KP.ru } & 806 & Рассказ очевидца & 0,339 & 0,083 & 0 \\
\hline & 1505 & Виноваты люди & 0,333 & 0,103 & 0,002 \\
\hline Lenta.ru & 904 & $\begin{array}{l}\text { Пользовательский } \\
\text { контент }\end{array}$ & 0,833 & 0,285 & 0,013 \\
\hline
\end{tabular}

контента» (категории 901-905), «ответственность» (категории 1501-1506). В процессе регрессионного анализа по методу шагового отбора были выделены показатели, которые тесно связаны с исследуемой категорией и могут рассматриваться как ее предикторы. Результаты регрессионного анализа позволяют увидеть, как именно представляются страдания людей в разных изданиях (см. табл. 4).

Согласно полученным результатам, тема страданий в различных изданиях подается по-разному. Психологическое значение этих стратегий различно. Так, RG.ru снимает вопрос об ответственности, апеллируя к непредсказуемости природы, случайности, тем самым способствует формированию образа хаотического неуправляемого мира. Тема страданий возникает преимущественно в видеоматериалах (категория 808), журналист ссылается на мнение поль- зователей (категория 406), при этом в публикации делается упор на безличную причину - непредсказуемость природы (категория 1506).

КР.ru фиксируется на устрашающих подробностях произошедшего, предоставляя слово напуганным очевидцам, при этом пытается усмотреть в несчастье человеческий фактор, возлагая вину на самих участников событий. В материалах КР.ru страдания эмоционально описываются очевидцами (категория 806), а вина возлагается на рядовых людей (категория 1506).

Lenta.ru просто транслирует материалы, созданные самими пользователями, не обращая внимание на их травматическое содержание. В публикациях данного издания тема страданий обусловлена привлечением эмоционально заряженного пользовательского контента (категория 904). 
Таблица 5. Использование параинформационных приемов и примеров мобилизации (в среднем на статью)

\begin{tabular}{|l|c|c|c|}
\hline Издание & Нарративые & Лексико-семантические & Примеры мобилизации \\
\hline RG.ru & 2,22 & 1,65 & 1,26 \\
\hline KP.ru & 2,71 & 2,11 & 1,14 \\
\hline Lenta.ru & 2,79 & 2,36 & 1,21 \\
\hline
\end{tabular}

С точки зрения психологии травмы подача новостей в интернет-издании КР.ru наиболее травматична, так как педалирует чувства страха, вины и агрессии. Такая стратегия призвана не столько информировать аудиторию, сколько эксплуатировать ее эмоции.

\section{СМИ: психологическая мобилизация населения на преодоление трудностей?}

Известно, что приемы подачи травмогенных новостей могут как деморализовать аудиторию (вызвать страх и отчаяние), так и воодушевлять людей на активное сопротивление обстоятельствам (Пронина, 2011; Рыбалко, 2007; Трубицына, 2001). Интересно было проанализировать, в какой степени публикации журналистов в различных изданиях ориентируют аудиторию на преодоление трудностей и показывают примеры активных действий по устранению последствий стихийных бедствий.

Мы сравнили количество параинформационных приемов, педалирующих негативные эмоции, и примеры борьбы со стихией в среднем на одну статью для каждого издания. Из таблицы 5 видно, что примеров мобилизации мало, практически один на статью, в то время как параинформационных приемов, апеллирующих к отрицательным эмоциям страха, ужаса и отчаяния, около четырех, из них нарративных - более двух, лексико-семантических - чуть менее двух.

Чтобы выявить долю материалов, содержащих примеры мобилизации, мы сум- мировали все статьи, в которых упоминается какая-либо деятельность по решению проблемы. Больше всего примеров мобилизации выявлено в публикациях RG.ru 86\%, доля KP.ru и Lenta.ru оказалась меньше на 15\% (по 71\%).

При этом стоит отметить, что примеров активных действий со стороны государства и органов власти больше в RG.ru (63,73\% и 47,06\%) и Lenta.ru (57,14\% и 50\%), со стороны организаций и коммунальных служб в KP.ru (65,06\%). Показателей активности со стороны граждан, самостоятельно ликвидирующих последствия экстремального природного явления, оказалось мало во всех анализируемых онлайн-СМИ.

Таким образом, портал правительственной газеты RG.ru и интернет-СMИ Lenta.ru чаще пишут о роли государственных структур в преодолении бедствий, а KP.ru обращает внимание на роль муниципальных и общественных организаций. К сожалению, все три издания почти не дают примеров активного противостояния стихии со стороны обычных людей. А ведь это с точки зрения медиапсихологии наиболее «терапевтически» действующий фактор (Пронина, 2011: 147; Пронин, Пронина, 2013: 159).

Данные частотного анализа свидетельствуют о том, что на сайтах изданий, имеющих бумажный аналог, практически во всех случаях источником мнения является автор публикации (RG.ru - 100\%, KP.ru 98,8\%, Lenta.ru - 85,71\%). Мнение очевидцев и участников событий представлено в основном в материалах Lenta.ru (RG.ru - 
$17,65 \%$, KP.ru - 32,53\%, Lenta.ru - 42,86\%). Возможно, так проявляется «генетический код" издания: онлайн-платформы, имеющие в своем анамнезе печатную версию, отдают предпочтение мнению журналиста, выступающего от имени редакции, а вот СМИ, возникшие в Интернете, более легко делегируют полномочия коммуникатора рядовым представителям аудитории.

\section{Источники аудиовизуального контента и способ представления информации}

Значимые различия между изданиями касались и источников аудиовизуальной информации. Дискриминантный анализ по параметру «Источники аудиовизуального контента» (категории 901-905) показал, что отличительной чертой KP.ru является активное использование пользовательского контента, предоставляемого самой аудиторией (UGC), а характерной особенностью Lenta.ru - привлечение материалов из других СМИ. Доля статей, в которых используются материалы пользователей для разных изданий составила: $R G . r u-0,98 \%$, KP.ru-36,14\%, Lenta.ru-21,43\%.

Использование UGC при освещении природных бедствий имеет большое значение и может стать инструментом открытости и прозрачности коммуникации. Однако необходимо отметить, что журналисты изучаемых платформ при отборе материалов зачастую руководствовались принципом сенсационности, а порой и стратегией «информационного садизма».

\section{Информационные модели и стратегии СМИ}

Чтобы посмотреть, насколько издания в целом сходны между собой, мы суммировали все различия по всем категориям и рассчитали эвклидово расстояние между изданиями попарно. Это позволило наглядно представить взаимное сходство между объектами в виде геометрического рассто- яния между ними в n-мерном пространстве признаков (Беккенбах, Беллман, 1965: 124-125).

Эвклидово расстояние между точками $x$ и у в п-мерном пространстве (у нас 101 категория, значит, 101-мерное пространство по числу категорий контент-анализа) вычисляется по следующей формуле: $d(x-y)=$ $\sqrt{\Sigma} n i=1(x i-y i) 2$,

где «d $(x-y) »-$ это эвклидово расстояние между объектами «х» и «у» (например, между Lenta.ru и RG.ru);

(xi - yi) 2 - это квадрат разности между показателями двух изданий (например, Lenta.ru и RG.ru) по каждой категории;

$\sum n i=1(x i-y i) 2$ - это сумма квадратов разностей по всем категориям (у нас 101 категория, значит, $n=101$ ).

Таким образом, эвклидово расстояние между двумя изданиями - это квадратный корень из суммы квадратов разностей по всем категориям для этих двух изданий. Полученные геометрические расстояния между всеми изданиями условно представлены на рисунке 2.

Оказалось, что ближе всего друг к другу онлайн-платформы, имеющие в анамнезе печатную форму (RG.ru и KP.ru). Несмотря на всю очевидную разницу в форматах официальной газеты правительства и таблоида расстояние между ними в семантическом пространстве признаков наименьшее - 1,52. Напротив, массовые популярные издания KP.ru и Lenta.ru, которые могли бы претендовать на максимальное сходство, оказались друг от друга почти так же далеко (1,71), как официальное (RG.ru) и свободное (Lenta.ru) - 1,79.

Таким образом, по сумме различий Lenta. rи значительно отличается и от КР.ги и от $R G$.ru, несмотря на успешные попытки KP.ru перенять формат новых медиа - мультимедийность и интерактивность. Думается, основная причина различий в том, что Lenta. $r u$, не имея печатной версии, относится $\mathrm{K}$ другому поколению СМИ и ориентируется 


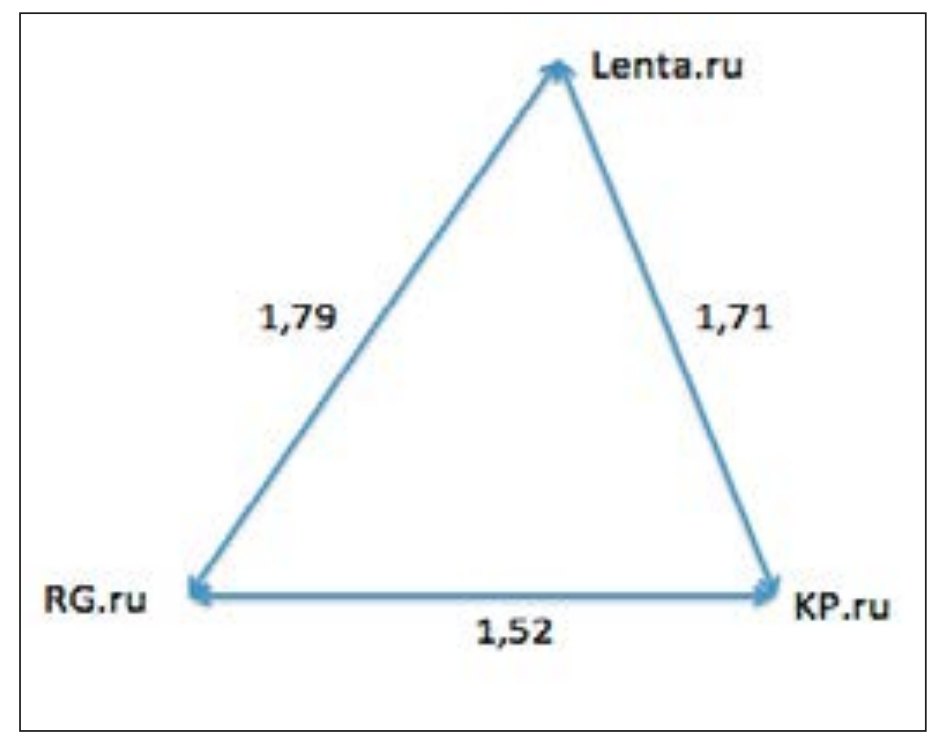

Рисунок 2. Эвклидово расстояние между изданиями попарно

на более диалогическую модель коммуникации, где новость важнее интерпретации, а мнение пользователя равноценно точки зрения журналиста.

\section{Заключение}

Проведенное исследование подтвердило различия в использовании параинформационных приемов, которые, как оказалось, связаны с ключевыми особенностями формата каждой из изучаемых онлайн-платформ. Ниже мы суммируем выявленные особенности:

RG.ru (сайт ежедневного качественного издания Правительства РФ, онлайн-аналог) - в освещении экстремальных природных явлений тяготеет к информационной парадигме; ограниченно использует параинформационные приемы, апеллирующие к эмоциям; субъектом мнения в тексте, как правило, выступает журналист; вопрос об ответственности за негативные последствия экстремального природного явления в текстах практически не затрагивается или выражен слабо, что вместе с апелляцией к непредсказуемости природы, случайности формирует образ хаотического неуправляемого мира; не использует UGC; мало задействует свои мультимедийные возможности (в основном - только фотоматериалы).

KP.ru (платформа массовой общенациональной общественно-политической газеты) - в освещении экстремальных природных явлений придерживается развлекательной парадигмы; подает события в особенно эмоциогенной, в условиях ЧС травматичной, форме (обладает склонностью к использованию стратегии «информационного садизма», то есть акцентирует внимание на устрашающих подробностях произошедшего, предоставляет слово напуганным очевидцам и возлагает вину на самих участников событий); субъектом мнения в тексте, как правило, выступает журналист; активно использует UGC и заимствует контент у других средств массовой информации; применяет все мультимедийные возможности (задействует все каналы передачи информации).

Lenta.ru (новостное общественно-политическое издание) транслирует материалы, 
в том числе созданные самими пользователями, в которых может присутствовать травматическое содержание; субъектом мнения в тексте, как правило, выступают не только журналисты, но также очевидцы и участники событий; ответственность за негативные последствия экстремального природного явления в основном возлагается на административные структуры; активно использует UGC; максимально реализует свои мультимедийные возможности.

Выявленные различия, как было показано, связаны, во-первых, с задачами издания, во-вторых, с широтой и интенсивностью использования новых электронныхтехнологий и, в-третьих, с «генотипом» издания, который может быть унаследован от старых СМИ или продолжает линию новых медиа.
По всей видимости, именно «генотип» издания оказывает определяющее влияние на характер предъявления информации. Так, издания, разные по функциям (официальное и развлекательное), а также по формату (активно и слабо использующие мультимедийные возможности), оказались ближе друг к другу, чем массмедиа, принадлежащие разным «поколениям» СМИ (возникшие в офлайн-среде до эпохи Интернета или непосредственно в интернетпространстве). Это заставляет задуматься над тем, что такое новые медиа как новый тип коммуникации, не только в технологическом, но и в медиапсихологическом смысле. Для уточнения сути этих различий, безусловно, необходимы дальнейшие исследования структуры текстов, .

\section{Примечания}

${ }^{1}$ Топ-10 самых цитируемых газет - октябрь 2017 / Медиалогия. Режим доступа: http://www.mlg.ru/ratings/media/federal/5642/\#gazeti (дата обращения: 17.03.2019).

2 Топ-30 самых цитируемых интернет-ресурсов - январь 2019 / Медиалогия. Режим доступа: https://www.mlg.ru/ratings/media/federal/6520/\#internet (дата обращения: 17.03.2019).

3 Киршева И. В Канске во время страшного пожара погибли два человека // KР.ru. 2017. Май, 25. Режим доступа: https://www.tumen.kp.ru/daily/26683.4/3706115/ (дата обращения: 17.03.2019).

4 Там же.

5 Сидоров Д., Стейнерт А., Лютых С. Погибли и ранены люди. Провал МчС // Lenta.ru. 2017. Май, 30. Режим доступа: https://lenta.ru/articles/2017/05/30/poslepotopa/ (дата обращения: 17.03.2019).

6 Беляева А. Грозит ли Ставрополью повторение наводнения 2002 года // KP.ru. 2017. Май, 24. Режим доступа: https://www.stav.kp.ru/daily/26682/3705929/?broadcast. number=1 (дата обращения: 17.03.2019).

7 UGC - от англ. user generated content - созданный пользователями контент, который может быть сделан специально для СМИ, получен из открытых источников или приобретен у любителей (Вартанова (ред.), 2015: 191). 


\section{Библиография}

Беккенбах Э., Беллман Р. Введение в неравенства. М.: Мир, 1965.

Бервенова О.В. Компенсаторные ресурсы средств массовой информации в чрезвычайных ситуациях: дис. ... канд. полит. наук. М., 2007.

Конецкая В.П. Социология коммуникации. М.: Междунар. ун-т бизнеса и управления, 1997.

Медиасистема России: учеб. пособие / под ред. Е.Л. Вартановой. М: Аспект Пресс, 2015.

Полищук Ю.И. О негативном влиянии средств массовой информации на психическое здоровье // Независимый психиатрический журнал. 2003. № 1. С. 62-65.

Пронина Е.Е. Категории медиапсихологии: факты, феномены, фантомы // Человек как субъект и объект медиапсихологии. М.: Ин-т человека; Изд-во Моск. ун-та, 2011. C. 105-150.

Пронин Е.И., Пронина Е.Е. Медиапсихология: новейшие информационные технологии и феномен человека // Общественные науки и современность. 2013. № 2. С. 151-161.

Рыбалко О.М. Психологическая защита индивида от информационного травмирования посредством масс-медиа в чрезвычайных ситуациях // Мат. IV Всерос. съезда Российского психологического общества. Ростов-н/Д., 18-21 сентября 2007 г. С. 120-121.

Трубицына Л.В. Средства массовой информации и психологическая травма // Проблемы медиапсихологии: мат. секции «Медиапсихология» Междунар. науч.практ. конф. «Журналистика в 2000 году: Реалии и прогнозы развития». М., 2001. Режим доступа: http://evartist.narod.ru/text7/41.htm 